\title{
Evaluating the serological applications of Toxoplasma gondii rhoptry protein 1 (ROP1) antigen
}

\author{
Fatemeh Keshavarzi ${ }^{1 *}$, Parviz Ashtari ${ }^{2}$, Pirooz Ebrahimi ${ }^{3}$
}

1. Department of Biology, Sanandaj Branch, Islamic Azad University, Sanandaj, Iran

2. Radiation Application Research School, Nuclear Science and Technology Research Institute, Tehran, Iran

3. Sapienza University of Rome, Yas Women Hospital, Tehran

*Corresponding author:Tel: +98 9183704918 Fax: +98 8333288661

Address: Department of Biology, Sanandaj Branch, Islamic Azad University, Sanandaj, Iran

E-mail:gol.keshavarzi@gmail.com

Received; 2016/06/3 revised; 2016/07/22 accepted; 2016/09/25

\section{Abstract}

Introduction: Toxoplasma gondii ( $T$. gondii) is distributed worldwide and infects most species. The serious incidence and severe or fatal injury caused by $T$. gondii infection clearly indicates the necessity for the event of a vaccine. The current study goals were to evaluate serological applications of Toxoplasma gondiirhoptry protein 1 (ROP1) antigen.

Materials and methods: We created a polymer vaccine by using the eukaryotic plasmid, pROP1. Purification by one-step metal affinity chromatography allowed recovery of milligram amounts of purified recombinant proteins per liter of culture. The quality of this matter for diagnosing of human infections was provided and tested on 77 serum samples which were obtained during routine diagnostic tests. A panel of 20 serum samples from patients with acute toxoplasmosis was compared to a panel of 35 serum samples from individuals with chronic toxoplasmosis.

Results: Results of the study indicated that antibodies detected from patients with acute and chronic infections were $96 \%$ and $17 \%$, respectively, by using of pROP1 recombinant antigen. Conclusion: According to the present study an immunoglobulin G antibody against ROP1 antigen is made throughout the acute stage of toxoplasmosis infection, but not in the chronic phase of toxoplasmosis.

Keywords: Toxoplasma gondii, ROP1, Recombinant antigen, Acute toxoplasmosis

\section{Introduction}

Toxoplasma gondii (T. gondii) is a parasite belonging to the Apicomplexa $(1,2)$. This parasite is distributed across worldwide and infects most species of animals and humans. Toxoplasmosis is immune competent in adults and is usually asymptomatic.

Toxoplasmosis is a main cause of fatality in congenitally infected patients and immune compromised patients (3-5). The live vaccine is dangerous because of the reversing to pathogenic phenotype and low shelf life. Additionally, DNA vaccines can exert potent, long-lasting humeral and cellmediated immunity $(6,7) . T$. gondii infections usually promote to activate $\mathrm{CD} 4^{+}$ and $\mathrm{CD}^{+} \mathrm{T}$ cells, simultaneously $(7,8)$. Like others unicellular organisms $T$. gondii is composed of various antigens. Somatic and excreted/secreted antigens are the most important Toxoplasma antigens that the secreted ones can activate potent immune response $(9,10)$. In the present study, we constructed a plasmid expressing the ROP1 antigen (pROP1), then examined their expression in eukaryotic cells and evaluated the usefulness of the $T$. gondii recombinant r-ROP1 antigen for diagnostic purposes. The antigenicity of recombinant antigen against human serum samples was 
evaluated by Western blotting and ELISA analysis.

\section{Material and methods}

Animals and $T$. gondii strains: Some old female BALB/c mice were purchased and kept under sterile in animal laboratory of theSanandaj Azad University. A highly virulent strain of $T$. gondii preserve $(\mathrm{RH}$ strain) in BALB/c mice was used for production of tachyzoites.

DNA extraction and polymerase chain reaction: About $5 \times 10^{7}$ tachyzoites $(100 \mu \mathrm{l})$ were concentrated by centrifugation and washed with phosphate buffer saline and then lysed in $900 \mu 1$ lysis buffer and then treated with $10 \mu \mathrm{l}$ proteinase $\mathrm{K}(100 \mu \mathrm{g} / \mathrm{ml})$ at $55^{\circ} \mathrm{C}$ for $2 \mathrm{~h}$. The proteins were removed by adding an equal volume of phenol/chloroform to lysate. The lysate tube was centrifuged (13000 RPM /15 min) and an equivalent volume of chloroform was added to the supernatant. DNA pellet was obtained after adding equal content of $100 \%$ ethanol and $1 / 10$ volume of $3 \mathrm{M}$ sodium acetate to this supernatant and centrifugation at $13000 \mathrm{RPM}$ for $10 \mathrm{~min}$ and then washing with $70 \%$ ethanol. The DNA pellet dissolved in sterile distilled water and stored at $-20^{\circ} \mathrm{C}$ until use. Extracted DNA products were examined on $0.8 \%$ agarose gel. The sequence provided by digestion of BglII and HindIIIwas designed for cloning. From the GenBank database (http://www.ncbi.com) we took the sequences of the gene encoding ROP1 antigen of $T$. gondii (accession no. M71274).

The forward $(F)$ and reverse $(\mathrm{R})$ sequences of primers were appropriately determined as follow:

F: GTGCCAGATCTAGCGTCGCATTCTCATTCG R: CCAAAGCTTTTGCGATCCATCATCCTGCTCTG The DNA segment of rop1 (corresponding to nucleotides 252 to 1188 ) encodingROP1 was obtained by PCR using above primer. DNA extracted from tachyzoites was used as a template to amplify the ROP1 gene by PCR performed in $25 \mu 1$ of solution containing $3 \mu \mathrm{l}$ of template DNA, $0.5 \mu \mathrm{l}$
TaqDNA polymerase, $2.5 \mu \mathrm{l} 10 \mathrm{X}$ PCR buffer, $0.75 \mu \mathrm{l} \mathrm{MgCl} 2,15.75 \mu \mathrm{l}$ distilled water and $1 \mu \mathrm{l}$ each of primers under the following conditions: After an early $5 \mathrm{~min}$ denaturation at $94^{\circ} \mathrm{C}$, each cycle consisted of 60 s at $94^{\circ} \mathrm{C}, 30 \mathrm{~s}$ at $62^{\circ} \mathrm{C}$ and 60 sat $72^{\circ} \mathrm{C}$ at the end of the 32 cycles of amplification and $30 \mathrm{~min}$ at $72^{\circ} \mathrm{C}$ was final extension. The PCR products checked out by electrophoresis on a $1 \%$ agarose gel and taken a photo. The molecular weight markers used were the $1 \mathrm{kbp}$ DNA ladders (Fermentas).

Cloning of ROP1: The pUET1 cloning vector was used and ligation was done according to our previous study (11). The ligation product used to transform and was accomplished Escherichia coli BL21 plus. Competent cell was prepared and the ligation output was a shiftin competent cell. According to protocol(12) retrieved in Luria-Bertani (LB) broth and LB broth medium free antibiotic by incubating at 37 ${ }^{\circ} \mathrm{C}$ for 2 hours and then were plated onto LB agar plates contained IPTG $200 \mathrm{mg} / \mathrm{ml}$, ampicillin $100 \mathrm{mg} / \mathrm{ml}$ and X-Gal $20 \mathrm{mg} / \mathrm{ml}$, and plates were incubated at $37^{\circ} \mathrm{C}$ for overnight to screening white and blue colonies. The selected colony of both color passages in LB broth or LB agar incubated at $37{ }^{\circ} \mathrm{C}$ for an overnight. Based on the protocol, DNA plasmid was extracted and the cloned ROP1 was verified by PCR, nucleotide sequencing and restriction digestion.

Sub-cloning of the pT-ROP1 inpcDNA3eukaryote expression vector: The digested pT-ROP1by EcoR1 and HindIII inserted into the digested pcDNA3 vector and the inserted product was transformed into $\mathrm{CHO}$ cells (competent cells). The plasmid was extracted and identify by electrophoresis, PCR amplification and restriction digestion (11). SDS-PAGE and Western blot analysis: After 48h, pellets of transfected cells were suspended in $150 \mathrm{ml}$ SDS-PAGE sample buffer and then sonicated and heated $\left(100^{\circ} \mathrm{C} / 5 \mathrm{~min}\right)$. Lysates were separated on a $12 \%$ polyacrylamide gel, transferred to 
poly vinyl idenedifluoridecoats, and then blocked with Tris-buffered saline $(20 \mathrm{mM}$ Tris, $137 \mathrm{mM} \mathrm{NaCl}, \mathrm{pH} 7.6$ ) containing $0.1 \%$ Tween 20 and 5\% skim milk. Membranes were washed with buffer and then for 2 hours at room temperature mixed with primary antibody of mouse antiFLAG. Interested antibody was washed out with TBST. Peroxidase activity was a study using enhanced chemoluminesce (ECL) Western blotting detection system.

ELISA assay: MaxiSorp multi well plates were coated with $0.1 \mathrm{ml}$ of $\mathrm{r}-\mathrm{ROP} 1$ protein at a final concentration of $1 \mathrm{~g} / \mathrm{ml}$ for antigen in a coating buffer $(0.05 \mathrm{M}$ carbonate buffer, $\mathrm{pH}$ 9.6). Control plates were incubated at $4^{\circ} \mathrm{C}$ with the extract recombinant proteins as mentioned above. After overnight, controls were washed (PBS- $0.1 \%$ Triton $\mathrm{X}-100)$ and blocked $\left(37^{\circ} \mathrm{C}\right.$ for 1 hour) by using blocking solution ( $1 \%$ bovine serum albumin-1\% Triton X-100-PBS). Afterward, they were covered (1hour at $37^{\circ} \mathrm{C}$ ) with human serum specimens diluted 1:100 in the blocking solution. Plates were washed with PBS- $0.1 \%$, Triton X-100 and added to each well from the conjugates of anti-human IgG peroxidase-labeled (1 $\mathrm{mg} / \mathrm{ml}$ ), diluted 1: 4,000 in blocking solutions. Next, the plates were incubated $35 \mathrm{~min}$ at $37^{\circ} \mathrm{C}$ and then washed. Finally, by incubating the plates with ophenylene diamine dihydrochloride chromogenic substrate was revealed enzymatic activity. After $40 \mathrm{~min}$ at $37^{\circ} \mathrm{C}$ in darkness, by adding $0.1 \mathrm{ml}$ of $1 \mathrm{M}$ sulfuric acid was stopped the color development reaction and the color intensity was measured using a Microtiter plate reader at $490 \mathrm{~nm}$. Each serum sample was examined and calculated of the optical density (OD) reading.

Serum samples: A total of 77 healthy human serum samples was analyzed and based on serological profiles divided into three classes. The class I consisted of 20 human serum specimens from patients in the acute phase of toxoplasmosis. The presences of specific IgM, antibodies were measured by IgM-ELISA Vistas'. All serum samples had positive IgG antibodies. Class II consisted of 35 human serum samples from patients with chronic toxoplasmosis. By an absence of specific IgM antibodies and an antibody avidity test evaluated all those serum samples had positive IgG antibodies high avidity. Class III (the control group) included 22 human serum samples from serious negative individuals. For more, statistical analysis of the ELISA results was evaluated with the Microsoft Excel schedule for assessment of the 2 test.

\section{Results}

The sequence analysis verified that PCRcreated change and the resulting vector included of 1686 base pairs (accordance with Gene Bank, Z36906.1) from ROP1 gene. ROP1 indicated in vitro by transfected $\mathrm{CHO}$ cells (competent cells) ROP1 was synthesized during an organism system (Figures 1, 2 and 3).

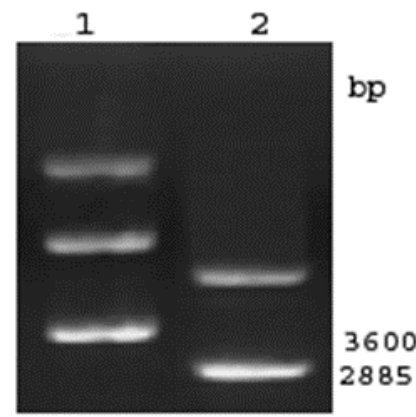

Figure1. Figure shows the result of electrophoresis pUET1 and pT-ROP1 plasmids. Lane 1: Plasmid extracted from pT-ROP1 and Lane 2: Plasmid extracted from pUET1.

The CHO cells (transfected and nontransfected control cells) were produced for $48 \mathrm{~h}$ following the transaction and list in sample buffer. The ROP1 antigen described in detail as soluble protein with calculated molecular weight $39 \mathrm{kDa}$. The immune action of the purified antigen r-ROP1 was tested by Western blot analysis with 4 human serum samples selected from each of the three serum sample groups that we were assayed (Figure 4). IgG antibodies present in serum group I samples in the serious stage of toxoplasmosis efficiently identified the r-ROP1 antigen. In contrast, 
IgGs from patients group II in the continuous stage of infection reacted weakly with Rop1. Moreover, immunoreactions of r-ROP1 antigen with serum samples from healthy patients (group III) was not studied.

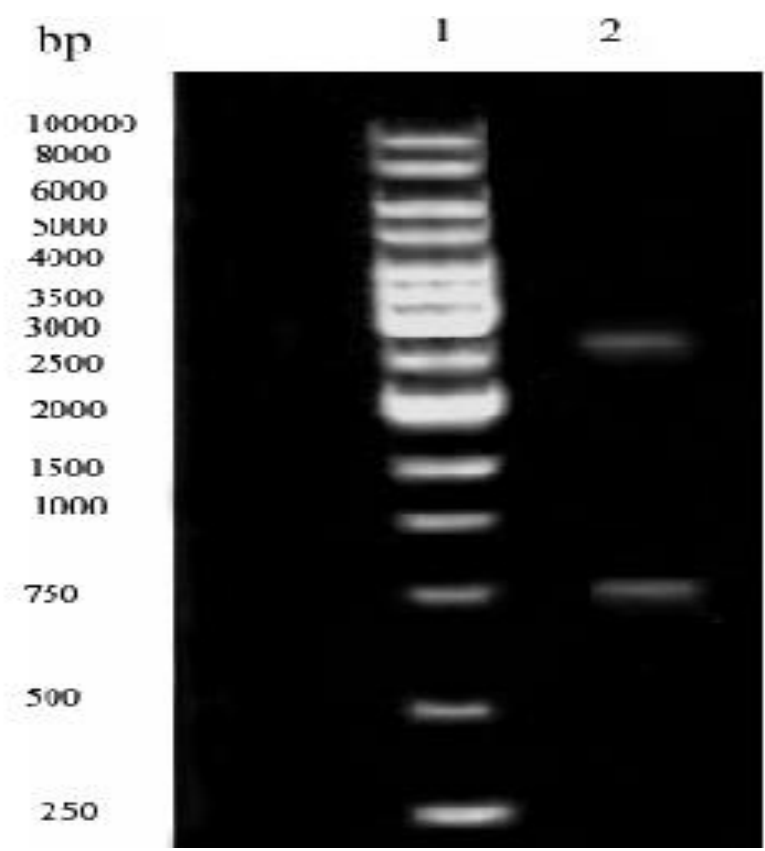

Figure 2. Digestion of extracted pT-ROP1 after RANs formation. Lane1: ladder 1kb, Lanes 2: (ROP1 757bp, pUET12876 bp).

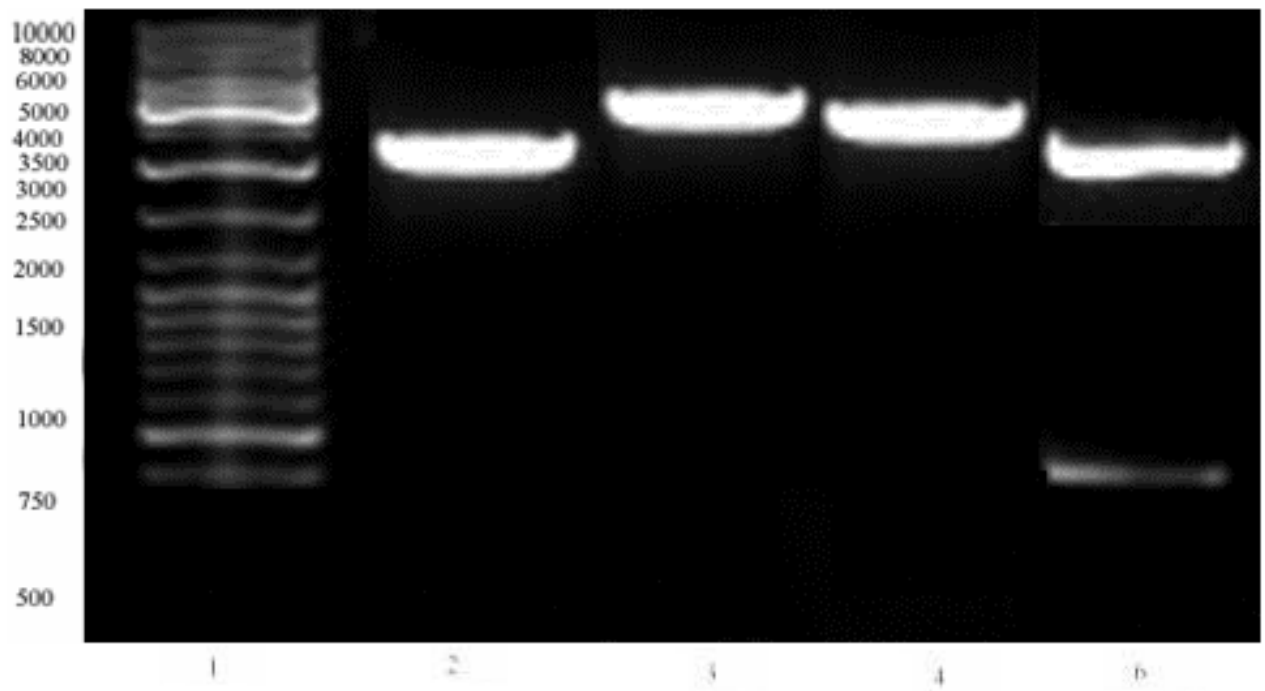

Figure 3. Detection of pcDNA3-ROP1 by enzyme Digestion. Lane1: ladder 1kb, 2: pcROP1, 3: pc-ROP1 after digestion EcoRI enzyme, 4: pc-ROP1 after digestion with HindIII and 5: pcROP1 after digestion with each other enzymes (ROP1 $\sim 760 \mathrm{bp})$. 


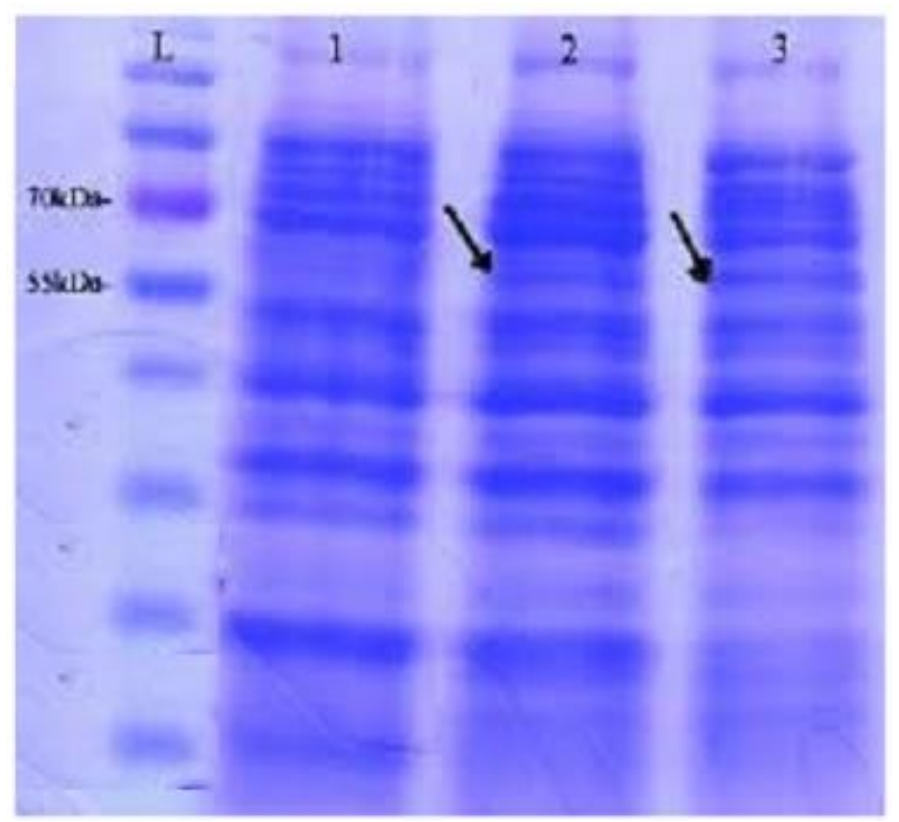

Figure 4. Expression of Recombinant ROP1 Protein in SDS-PAGE gel. L: protein size marker; Lane 1: p-ROP1 before induction without expected protein, Lane 2 and 3: p-ROP1 after induction that expressed expected protein.

\section{Discussion}

Chen et al. cloned a 750bp fragment of T. gondii ROP1 sequence into PUC18 cellular inclusion so transferred it to pcDNA3 organism expression cellular inclusion (12).

Another group constructed a fusion-based recombinant plasmid (pSAG1-ROP1).By liposome-entrapped particles Recombinant plasmids were injected into Balb/c mice and immune responses were analyzed (13).The recombinant antigenic proteins are encouraging tools that can be used in diagnostic tests for the between serious and constant infections. Aubert et al. producedROP1 in fusion with cks protein of E.coli and to identify specific $\operatorname{IgM}$ and IgG antibodies of toxoplasmosis in human serum used these recombinant antigens (14).The fragments of ROP1 and SAG1 genes into pRP261 expression vector cloned and used the resulting explicit proteins to serological assessment of toxoplasmosis in patients suffering from acute and chronic toxoplasmosis by Meek et al. (15).

In this research reported the bacterial production of $T$. gondii soluble r-ROP1 antigen protein by the use of the effective expression system developed in our laboratory (11).This expression system and the method of disinfection by a one-step metal attraction chromatography led to the production of $14 \mathrm{mg}$ of r-ROP1 per liter of culture(11). In this work, we appraised the diagnostic avail and worthiness of T.gondii recombinant antigenic protein $\mathrm{r}-\mathrm{ROP} 1$ and then tested r-ROP1 restarts by the use of two separate classes of human serum parable show serious and constant infections. Both groups were analyzed by ELISA techniques and Western blot. IgG antibodies in serum samples from patients in the serious stage of toxoplasmosis(group I; serum samples with positive $\operatorname{IgM}$ and IgG at low enthusiasm) respond with the recombinant antigens more potent than those in serum specimens from patients in the constant state of toxoplasmosis(group II; serum samples with positive IgG at high acting and negative IgM. Thus, our results with r-ROP1 antigen imply that these recombinants can be used as serological indicator of recently obtained infection. The r-ROP1 antigen was shown before to be sensitive in its capability to discover IgG antibodies in serum samples from patients with toxoplasmosis (12-15). The usefulness of this antigen for diagnosis of human 
infections was provided and tested on 77 serum samples which are obtained during routine diagnostic tests. A panel of 20 serum samples from patients with acute toxoplasmosis was compared to a panel of 35 serum samples from individuals with chronic toxoplasmosis. The results indicated that ROP1 recombinant antigen detected antibodies further in individuals with acute infections (96\%) than in individuals with chronic infections (17\%). The results of this study show that special IgG anti-ROP1 antibodies are present in serum samples from patients at the serious stage of T. gondii infection. Successful use of recombinant antigenic proteins for the finding of anti-T. gondii- special antibodies

\section{References}

1. Ossorio P, Schwartzman N, Boothroyd JC. Toxoplasma gondii rhoptry protein associated with host cell penetration has unusual charge asymmetry. Mol Biochem Parasitol J. 1992; 50(1):1-16.

2. Jenum PA, Stray-Pedersen B, Gundersen AG. Improved diagnosis of primary Toxoplasma gondii infection in early pregnancy by determination of anti-toxoplasma immunoglobulin G avidity. J Clin Microbiol. 1997; 35(8):1972-7.

3. Dannemann BR, Vaughan WC, Thulliez P, Remington JS. Differential agglutination test for diagnosis of recently acquired infection with Toxoplasma gondii. J Clin Microbiol. 1990; 28(9):1928-33.

4. Fischer HG, Stachelhaus S, Sahm M, Meyer HM, Reichmann G. GRA7, an excretory $29 \mathrm{kDa}$ Toxoplasma Gondi dense granule protein released by infected host cells. JMolBiochemParasitol. 1998; 91(2):251-62.

5. Griner PF, Mayewski RJ, Mushlin AI, Greenland P. Selection and interpretation of diagnostic tests and procedures. Principles and applications. J Ann Intern Med. 1981; 94(4Pt2):55792. has been reported by a number of authors (15-16).

\section{Conclusion}

These data imply thatROP1 antigen is specifically encouraging candidates for efficient vaccine against toxoplasmosis. Additionally, results suggest that an immunoglobulin $\mathrm{G}$ antibody against ROP1 antigen is created during the acute stage of infections but not generally in the persistent phase of the sickness.

\section{Acknowledgment}

This study was supported by a grant from Islamic Azad University of Sanandaj, Iran.

6. Meek B, van Gool T, Gilis H, Peek R. Dissecting the IgM antibody response during the acute and latent phase of toxoplasmosis. Diagn Microbiol Infect Dis. 2001;41(3):131-7.

7. HarningD, Spenter J, MetsisA, Vuust J, Petersen E. Recombinant Toxoplasma gondii surface antigen 1 (P30) expressed in Escherichia coli is recognized by human Toxoplasmaspecific immunoglobulin $\mathrm{M}(\operatorname{IgM})$ and IgG antibodies. ClinDiagn Lab Immunol J. 1998; 3(3):355-7.

8. Hofgartner WT, Swanzy SR, Bacina RM, Condon J, Gupta M, Matlock PE, et al. Detection of immunoglobulin $\mathrm{G}$ (IgG) and IgM antibodies to Toxoplasma gondii: Evaluation of four commercial immunoassay systems. J Clin Microbiol. 1997; 35(12):3313-5.

9. Kim K, BulowR, Kampmeier J, Boothroyd JC. Conformationally appropriate expression of the Toxoplasma antigen SAG1 (p30) in CHOcells. J Infect Immun.1994; 62(1):203-9.

10. Pouletty P, Kadouche J, GarciaGonzalez M, Mihaesco E, Desmonts G, Thulliez $\mathrm{P}$, et al .An anti-human $\mathrm{m}$ chainmonoclonal antibody: use for detection of IgM antibodies to 
Toxoplasma gondii by reverse immunosorbent assay. J Immunol Methods. 1985; 76(2):289-98.

11. Keshavarzi F, Ashtari P. Expression of complete rhoptry protein1 (ROP1) gene of Toxoplasma gondii in Eukaryotic cell. AJBS. 2013; 6(7): 340-6.

12. Chen G, GuoH, LuF, ZhengH. Construction of a recombinant plasmid harbouring the rhoptry protein 1 gene of Toxoplasma gondii and preliminary observations on DNA immunity. Chin Med J (Engl). 2001; 114(8):837-40.

13. Chen $H$, Guo H. Induction of immune respons $\neg$ es in mice by vaccination with Liposome-entrapped DNA complexes encoding Toxoplasma gondii SAG1 and ROP1 genes. Chin Med J (Engl). 2003; 116(10):1561-6.
14. Aubert D, Maine GT, Villena I, Hunt JC, Howard L, SheuM. Recombinant antigens to detect Toxoplasma gondiispecific immunoglobulin $G$ and immunoglobulin $\mathbf{M}$ in human sera by enzyme immunoassay. J Clin Microbiol. 2000; 38(3):1144-50.

15. Meek B, Diepersloot RJ, Gool T, Speijer D, Peek R. IgM recognition of recombinant Toxoplasma gondii antigens by sera of acutely or latently infected humans. Diagn Microbiol Infect Dis.2003; 45(1):45-52.

16. McLeod R, Mack D, Brown C. Toxoplasma gondii: new advances in cellular and molecular biology. J Exp Parasitol.1991; 72(1):109-21. 